\title{
Tolerância ao estresse térmico em genótipos de trigo
}

\author{
Adeliano Cargnin ${ }^{(1)}$, Moacil Alves de Souza ${ }^{(2)}$, Valterley Soares Rocha( ${ }^{(2)}$, \\ Juarez Campolina Machado( ${ }^{(3)}$ e Edvandro Piccini(2)
}

\begin{abstract}
(1)Universidade Federal de Viçosa (UFV), Dep. de Genética e Melhoramento, Av. P.H. Rolfs, s/no, CEP 36571-100 Viçosa, MG. E-mail: adelianoc@hotmail.com (2)UFV, Dep. de Fitotecnia. E-mail: moacil@ufv.br, vsrocha@ufv.br, edipiccini@yahoo.com.br (3)Universidade Federal de Lavras, Caixa Postal 3037, CEP 37200-000 Lavras, MG. E-mail: juarezcmachado@yahoo.com.br
\end{abstract}

\begin{abstract}
Resumo - O objetivo deste trabalho foi verificar o efeito do estresse térmico sobre a cultura do trigo e avaliar o grau de tolerância de genitores e populações segregantes a esse estresse, de modo a identificar populações promissoras para obtenção de linhagens adaptadas às condições de Brasil Central. Foi utilizado o sistema de dialelo circulante, com oito genitores das cultivares Aliança, Anahuac, BH 1146, BR 24, BRS 207 e Pioneiro e as linhagens CPAC 9662 e EP 93541. Foram avaliadas 30 famílias $\mathrm{F}_{2: 4}$, oriundas de cada uma das oito populações segregantes, e os oito genitores. Os experimentos foram conduzidos em campo, em 2004, com semeadura no verão (condição de estresse térmico) e no inverno (condição favorável). Foi utilizado o delineamento em látice com duas repetições. Avaliaram-se os caracteres ciclo até o espigamento, altura de planta, peso médio do grão e produção de grãos. A alta temperatura causou redução em todos os caracteres avaliados e os efeitos do estresse térmico, ocorridos no verão, foram obtidos pela porcentagem dessa redução em comparação ao cultivo de inverno. Houve diferenças entre genótipos nas duas épocas de semeadura. Os materiais mais tolerantes ao calor foram os genitores Anahuac, BH 1146, BR 24 e EP 93541, e as populações segregantes Aliança/EP 93541, EP 93541/CPAC 9662 е BH 1146/BR 24.
\end{abstract}

Termos para indexação: Triticum aestivum, variabilidade genética, temperatura, seleção.

\section{Tolerance to thermic stress in wheat genotypes}

\begin{abstract}
The objective of this work was to verify the effect of thermic stress conditions on the wheat culture, to evaluate the tolerance level of parents and segregant populations to these conditions, as well as to identify promising populations in order to obtain lines adapted to the Brazilian Central region. A circulant dialel was used among eight parents, comprising the cultivars Aliança, Anahuac, BH 1146, BR 24, BRS 207 and Pioneiro; and the lines CPAC 9662 and EP 93541. Thirty $\mathrm{F}_{2: 4}$ families descending from the eight segregant populations and the eight genitors were evaluated. Experiments were carried out in the field and the sowings were performed in the summer (heat stress condition) and winter (favorable condition) of 2004. The lattice design with two replicates was used. Days to heading, plant height, average grain weight, and grain yield were evaluated. In the summer, high temperature reduced all characters evaluated, and thermic stress effects were determined by that reduction percent in comparison to winter cropping values. Differences among genotypes in both sowing dates were also observed. The most heat-tolerant materials were the parents Anahuac, BH 1146, BR 24 and EP 93541, and the segregant populations Aliança/EP 93541, EP 93541/CPAC 9662, and BH 1146/BR 24.
\end{abstract}

Index terms: Triticum aestivum, genetic variability, temperature, selection.

\section{Introdução}

A identificação de novas áreas promissoras para o cultivo do trigo no Brasil vem merecendo especial atenção. A migração do trigo em direção aos pólos e ao Equador pode ser atribuída à seleção natural e ao desenvolvimento, pelo homem, de novas cultivares adaptadas às condições ambientais específicas. Segundo Mota (1982), cultivares adaptadas são cultivadas desde o Equador até $60^{\circ}$ de latitude.

O principal entrave da cultura do trigo, na Região Central do Brasil, é a ocorrência de temperaturas muito elevadas durante todo o ciclo da cultura. O excesso de calor afeta, negativamente, vários caracteres das plantas e, como conseqüência, há redução da produtividade de grãos (Souza \& Ramalho, 2001). Desde os primórdios 
da pesquisa com a cultura do trigo, nesta região, por volta de 1930, uma das maiores preocupações dos melhoristas é o desenvolvimento de cultivares com maior tolerância ao calor (Souza, 1999), principalmente em cultivos de sequeiro, cujas semeaduras ocorrem no final do verão, especificamente de fevereiro até meados de março (Souza, 1979, 1983).

Do mesmo modo, no cultivo de inverno com irrigação, o estresse térmico constitui fator limitante em regiões do Brasil Central, situadas em altitudes inferiores a $800 \mathrm{~m}$, com redução de até 50\% na produtividade (Souza, 1999), a qual tem superado $7.500 \mathrm{~kg} \mathrm{ha}^{-1}$, em lavouras de Minas Gerais e Goiás (Embrapa Trigo, 2004), situadas em altitude média acima de $800 \mathrm{~m}$.

Para Yang et al. (2002), a senescência, caracterizada pela clorose das folhas e maturidade precoce do grão, é a primeira resposta das plantas de trigo às altas temperaturas, o que ocasiona forte redução no rendimento de grãos e de seus componentes. Essas observações concordam com resultados de pesquisa realizada por Khanna-Chopra \& Viswanathan (1999), que relatam que a redução do rendimento de grãos de trigo, cultivado sob estresse térmico, pode ser causada pela acelerada fase de desenvolvimento, acelerada senescência, aumento na taxa respiratória, redução na fotossíntese e conseqüente inibição da síntese do amido, durante o desenvolvimento do grão.

Para cada fase de desenvolvimento da planta de trigo existe uma faixa de temperatura ótima (McMaster, 1997). Entretanto, estudos de genética da tolerância ao calor têm sido concentrados na fase de planta adulta (após a antese), principalmente quando se utiliza a produção de grãos como característica indicadora das diferenças de comportamento dos diferentes genótipos, quando submetidos ao estresse térmico (Souza \& Ramalho, 2001).

A existência de variabilidade genética, quanto à tolerância ao calor em plantas de trigo, tem sido constatada em alguns trabalhos (Stone \& Nicolas, 1998; Khanna-Chopra \& Viswanathan, 1999; Ibrahim \& Quick, 2001; Yang et al., 2002); contudo, no Brasil, esse tipo de pesquisa é pouco freqüente. A maioria dos resultados encontrados sobre esse assunto é obtida em condições controladas, utilizando-se como base caracteres fisiológicos. Os resultados desses trabalhos devem ser utilizados em complementação às pesquisas que envolvem caracteres agronômicos, visto que as condições em que foram encontrados não refletem o que de fato ocorre no campo.
No Brasil, Souza \& Ramalho (2001), em trabalho realizado com o caráter rendimento de grãos em campo, constataram a existência de variabilidade genética e comportamento diferenciado de tolerância ao calor, entre as principais cultivares recomendadas para a Região do Brasil Central.

Dessa forma, a obtenção de informações sobre a existência de variabilidade genética da tolerância ao calor e do comportamento de genitores e populações segregantes, cultivados em diferentes épocas de semeadura, simulando-se o efeito da alta temperatura em campo, é importante para que se tornem mais eficientes os programas de melhoramento a serem conduzidos para a cultura do trigo no Brasil.

O objetivo deste trabalho foi verificar o efeito do estresse térmico sobre a cultura do trigo e avaliar o grau de tolerância de genitores: e populações segregantes a esse estresse, de modo a identificar populações promissoras, para obtenção de linhagens adaptadas às condições do Brasil Central.

\section{Material e Métodos}

Os experimentos foram conduzidos em campo, em 2004, na Estação Experimental de Coimbra, MG, pertencente à Universidade Federal de Viçosa (UFV), no Município de Coimbra, MG, a $20^{\circ} 45^{\prime} \mathrm{S}, 42^{\circ} 51^{\prime} \mathrm{W}$ e altitude de $720 \mathrm{~m}$.

Foram avaliadas oito populações segregantes, cada uma composta de 30 famílias $\mathrm{F}_{2: 4}$, oriundas do cruzamento entre oito genitores: as cultivares Aliança, Anahuac, BH 1146, BR 24, BRS 207 e Pioneiro (inicialmente denominada linhagem IVI 931009), e as linhagens CPAC 9662 e EP 93541. Utilizou-se o esquema de dialelo circulante, de acordo com Bearzoti (1997).

Foram utilizadas duas épocas de semeadura, uma para cada experimento. A primeira, denominada verão (condição de estresse), foi realizada no fim de janeiro (dia 30), quando predominam temperaturas elevadas durante o ciclo da cultura. A segunda época de semeadura, denominada inverno (condição favorável), foi efetuada no início de maio (dia 2), período a partir do qual ocorrem temperaturas mais amenas durante a maior parte do ciclo da cultura.

As práticas culturais adotadas foram uniformes nas duas épocas de semeadura, a fim de se minimizar a influência de fatores bióticos e abióticos no crescimento e no desenvolvimento da cultura, a não ser a alta 
temperatura, como fator causador de estresse térmico na expressão dos genótipos. Assim, ambos os experimentos foram irrigados sempre que necessário.

A adubação de manutenção foi realizada conforme os resultados das análises de solo executadas pelo Laboratório de Análises de Solos da UFV, aplicando-se $250 \mathrm{~kg} \mathrm{ha}^{-1}$ de NPK, da fórmula 8-28-16, no sulco de semeadura, e $50 \mathrm{~kg} \mathrm{ha}^{-1}$ de N em cobertura, no início do perfilhamento. Os demais tratos culturais foram realizados de acordo com as informações técnicas para a cultura do trigo (Reunião, 2003).

As 240 famílias (30 famílias de cada população segregante) e os oito genitores foram avaliados, utilizando-se o delineamento em látice com duas repetições. Foram utilizados, ainda, mais oito genótipos de trigo, a fim de se completar o número de tratamentos do látice. Cada parcela foi constituída de três linhas de $3 \mathrm{~m}$ de comprimento, no espaçamento de 0,30 m entre linhas, com 65 sementes aptas por metro, em área total de $2,7 \mathrm{~m}^{2}$.

Foram avaliados e coletados os dados referentes aos seguintes caracteres agronômicos: espigamento (dias); altura de planta $(\mathrm{cm})$; produção de grãos (grama por parcela); e peso médio dos grãos (miligrama por grão).

Os dados dos quatro caracteres avaliados nos dois ambientes, verão e inverno, foram submetidos à análise de variância, segundo o modelo matemático:

$\mathrm{Y}_{\mathrm{ijk}}=\mu+\mathrm{g}_{\mathrm{i}}+\mathrm{r}_{\mathrm{j}}+(\mathrm{b} / \mathrm{r})_{\mathrm{jk}}+\varepsilon_{\mathrm{ijk}}$, em que: $\mathrm{Y}_{\mathrm{ijk}}$ é o valor observado do tratamento $\mathrm{i}$, no bloco $\mathrm{k}$, dentro da repetição j; $\mu$ é a média geral do experimento; $g_{i}$ é o efeito do genótipo i ( $\mathrm{i}=1,2$... 256); $r_{j}$ o efeito da repetição $j(j=1,2)$; $(b / r){ }_{j k}$ é o efeito do bloco $k$, hierarquizado dentro da repetição $\mathrm{j}(\mathrm{k}=1,2 \ldots 16$, para $\mathrm{j}=1 \mathrm{e} \mathrm{k}=17,18 \ldots$ 32, para $\mathrm{j}=2$ ).

Foi feito, também, o desdobramento dos efeitos de populações e famílias dentro de cada população, a fim de se verificar a existência de variabilidade entre as oito populações e, também, entre as 30 famílias, dentro de cada uma das oito populações avaliadas, conforme o modelo matemático:

$\mathrm{Y}_{\mathrm{ijk}}=\mu+\mathrm{P}_{\mathrm{i}}+\mathrm{F} / \mathrm{P}_{\mathrm{ij}}+\mathrm{B}_{\mathrm{k}}+\varepsilon_{\mathrm{ijk}}$,

em que $Y_{\mathrm{ijk}}$ é o valor observado na parcela da k-ésima repetição, referente à j-ésima família da i-ésima população; $\mu$ é a média geral do ensaio; $\mathrm{P}_{\mathrm{i}}$ é o efeito fixo da i-ésima população $(\mathrm{i}=1,2 \ldots 8) ; \mathrm{F} / \mathrm{P}_{\mathrm{ij}}$ é o efeito fixo da j-ésima família dentro da i-ésima população ( $\mathrm{j}=1,2 \ldots 30) ; \mathrm{B}_{\mathrm{k}}$ é efeito aleatório da k-ésima repetição $(\mathrm{k}=1,2)$, e $\varepsilon_{\mathrm{ijk}}$ é o erro atribuído à parcela ijk.
Para o caráter produção de grãos, em as ambas épocas de semeadura, foi também estimada a contribuição relativa de cada população, para a variância total entre famílias das oito populações segregantes avaliadas.

Os agrupamentos de médias dos genitores e populações segregantes foram feitos com o teste descrito por Scott \& Knott (1974), que possibilita a definição de subconjuntos de genótipos que diferem significativamente entre si. Todas as análises foram feitas com o auxílio do programa computacional Genes (Cruz, 2001).

A quantificação dos efeitos do estresse de calor ocorrido no verão, em relação ao inverno, foi obtida pela porcentagem de redução, conforme a expressão de Wardlaw et al. (1989):

$\% \mathrm{R}=100\left[1-\left(\mathrm{P}_{\mathrm{v}} / \mathrm{P}_{\mathrm{i}}\right)\right]$

em que $P_{v}$ e $P_{i}$ são as médias de cada genótipo, nos experimentos de verão e inverno, respectivamente, para cada um dos caracteres avaliados. Posteriormente, os genótipos foram classificados em ordem crescente quanto aos seus porcentuais de redução (\%R).

\section{Resultados e Discussão}

As análises de variâncias evidenciaram diferenças significativas entre os genótipos, para todos os caracteres avaliados, tanto para o experimento com semeadura realizada no inverno quanto no verão, o que demonstra haver variabilidade genética, para esses caracteres, nos dois ambientes avaliados (Tabela 1).

Verifica-se a eficiência proporcionada pelo uso do delineamento em látice, em que se observam valores de até $47,36 \%$. Os coeficientes de variação dos experimentos encontram-se dentro de níveis aceitáveis para a cultura do trigo, e variam entre 2,63 e 12,67\% que, segundo Pimentel-Gomes (1990), podem ser considerados habituais para ensaios agrícolas. Assim sendo, essa precisão experimental torna praticáveis as inferências a partir dos dados analisados.

Ainda na Tabela 1, pode ser observado que, pelas discrepâncias das médias dos experimentos das duas épocas de semeadura, houve efeito da alta temperatura no verão (condição de estresse) sobre a cultura do trigo, que acarretou acentuada redução na expressão dos quatros caracteres. As diferenças acentuadas de temperaturas, entre as épocas de semeadura, contribuíram para que ocorresse diferença expressiva no desempenho das famílias. A produção média de grãos das famílias, por exemplo, foi de 444,57 g por parcela, no verão, contra 844,76 g por parcela, no inverno, ou seja, redução de $47 \%$. 
De fato, na semeadura de verão, as plantas de trigo foram submetidas, independentemente do estádio de desenvolvimento da cultura, a condições adversas de temperatura. Nesse período, as médias das temperaturas média, máxima e mínima foram superiores às médias do período de inverno (Tabela 2).

Longas horas de exposição à temperatura moderadamente alta, como também breves exposições à temperatura muito alta, ocasionam redução no rendimento da cultura do trigo, principalmente em cultivares que são sensíveis ao estresse térmico (Stone \& Nicolas, 1995).

As diferenças em produtividade entre as duas épocas de semeadura poderiam ser influenciadas, também, pelos efeitos do fotoperíodo. De fato, em fevereiro, o comprimento do dia é de aproximadamente 13 horas e, em maio, de 11 horas, ou seja, ocorre uma diferença em torno de duas horas entre as épocas de semeadura. Porém, ao trabalhar com as mesmas épocas de semeadura, Souza \& Ramalho (2001) verificaram que há diferenças entre cultivares de trigo, mas entre as épocas de semeadura, verão e inverno, os valores da soma térmica são praticamente os mesmos. Também existe acentuada diferença no ciclo, o que indica que a variação observada no ciclo até o espigamento foi determinada, predominantemente, pelos efeitos de temperatura entre as duas épocas de semeadura.

Para os demais caracteres, altura de planta e peso médio dos grãos, também foram verificadas diferenças entre as médias das duas épocas de semeadura, com redução dos dois caracteres no verão, em relação ao inverno (Tabela 1).

Desse modo, com a redução no ciclo da cultura até o espigamento tem-se, como provável conseqüência, a diminuição na altura de planta e o menor acúmulo de reservas, que acarretam menor peso médio dos grãos e, conseqüentemente, ocasionam menor produção de grãos. De acordo com Khanna-Chopra \& Viswanathan (1999), a redução do ciclo da cultura pode ocasionar a redução no acúmulo de matéria seca total, se as taxas de crescimento não são suficientemente altas para compensar essa redução sob estresse térmico.

Tabela 1. Resumo das análises de variâncias individuais de caracteres de famílias e genitores de trigo, avaliados em duas épocas de semeadura.

\begin{tabular}{|c|c|c|c|c|c|c|}
\hline Caráter & Época & Fonte de variação (\%) & GL & Quadrados médios & Média & CV $(\%)$ \\
\hline \multirow{6}{*}{$\begin{array}{l}\text { Produção de grãos } \\
\text { (g por parcela) }\end{array}$} & Inverno & Tratamento ajustado & 255 & $115.691,62 * *$ & 844,76 & 12,67 \\
\hline & & Erro efetivo & 225 & $11.446,86$ & & \\
\hline & & Efeito do látice & & 109,44 & & \\
\hline & Verão & Tratamento ajustado & 255 & $19.016,61 * *$ & 444,57 & 11,68 \\
\hline & & Erro efetivo & 225 & $2.697,63$ & & \\
\hline & & Efeito do látice & & 119,58 & & \\
\hline \multirow{6}{*}{$\begin{array}{l}\text { Peso médio dos grãos } \\
\text { (mg por grão) }\end{array}$} & Inverno & Tratamento ajustado & 255 & $23,71 * *$ & 49,32 & 3,60 \\
\hline & & Erro efetivo & 225 & 3,15 & & \\
\hline & & Efeito do látice & & 100,15 & & \\
\hline & Verão & Tratamento ajustado & 255 & $17,42 * *$ & 37,27 & 5,24 \\
\hline & & Erro efetivo & 225 & 3,81 & & \\
\hline & & Efeito do látice & & 107,24 & & \\
\hline \multirow{6}{*}{$\begin{array}{l}\text { Altura de planta } \\
(\mathrm{cm})\end{array}$} & Inverno & Tratamento ajustado & 255 & $297,92 * *$ & 108,75 & 3,97 \\
\hline & & Erro efetivo & 225 & 18,61 & & \\
\hline & & Efeito do látice & & 112,69 & & \\
\hline & Verão & Tratamento ajustado & 255 & $138,43 * *$ & 71,09 & 7,15 \\
\hline & & Erro efetivo & 225 & 25,81 & & \\
\hline & & Efeito do látice & & 147,36 & & \\
\hline \multirow{6}{*}{$\begin{array}{l}\text { Espigamento } \\
\text { (dias) }\end{array}$} & Inverno & Tratamento ajustado & 255 & $23,73 * *$ & 60,06 & 2,63 \\
\hline & & Erro efetivo & 225 & 2,50 & & \\
\hline & & Efeito do látice & & 119,12 & & \\
\hline & Verão & Tratamento ajustado & 255 & $20,40 * *$ & 47,07 & 3,65 \\
\hline & & Erro efetivo & 225 & 2,95 & & \\
\hline & & Efeito do látice & & 117,88 & & \\
\hline
\end{tabular}

**Significativo a $1 \%$ de probabilidade pelo teste $\mathrm{F}$. 
O processo de senescência, que é caracterizado pela clorose das folhas e causa a maturidade precoce da planta e, conseqüentemente, do grão, é a primeira resposta das plantas de trigo a altas temperaturas, fato este que acarreta forte redução no rendimento de grãos e de seus componentes Yang et al. (2002).

De fato, o excesso de calor causa efeitos diretos sobre a planta de trigo, reduzindo a eficiência fotossintética e aumentando a taxa de respiração. Como conseqüência ocorre redução da síntese de amido e da sua deposição no grão, que levam à diminuição do peso do grão e, conseqüentemente, afetam a produtividade da cultura (Khanna-Chopra \& Viswanathan, 1999).

O desdobramento do efeito de tratamentos evidenciou diferença significativa entre as oito populações avaliadas, demonstrando, desta forma, a existência de variabilidade genética entre as populações e entre famílias dentro de populações, para todos os caracteres, nas duas épocas de semeadura. Essa constatação aponta para a possibilidade de se extraírem linhagens superiores dessas populações, para as duas épocas de semeadura.

Como acontece para a maioria das grandes culturas, a produção de grãos é a característica mais importante em um programa de melhoramento genético. Assim, é importante que exista variabilidade genética entre as populações e, também, entre as próprias famílias dentro das populações, para se obterem ganhos com a realização da seleção.

A contribuição relativa de cada população, para a variância total entre as famílias das oito populações, permite identificar populações que

Tabela 2. Médias das temperaturas $\left({ }^{\circ} \mathrm{C}\right)$ médias, máximas e mínimas, registradas no posto meteorológico de Viçosa, MG, em 2004, nos diferentes estádios de desenvolvimento médio das plantas de trigo, nas semeaduras de inverno e verão.

\begin{tabular}{lccc}
\hline Estádio de desenvolvimento & Média & Máxima & Mínima \\
\hline \multicolumn{2}{c}{ Semeadura no inverno } \\
Emergência-perfilhamento & 17,41 & 23,15 & 14,01 \\
Perfilhamento-espigamento & 16,83 & 23,13 & 13,11 \\
Espigamento-maturação & 16,51 & 23,41 & 12,32 \\
Todo ciclo & 16,91 & 23,23 & 13,14 \\
\hline \multicolumn{3}{c}{ Semeadura no verão } \\
Emergência-perfilhamento & 22,12 & 27,45 & 19,02 \\
Perfilhamento-espigamento & 21,71 & 27,62 & 18,32 \\
Espigamento-maturação & 21,22 & 27,19 & 17,69 \\
Todo ciclo & 21,68 & 27,42 & 18,34 \\
\hline
\end{tabular}

apresentam elevada variabilidade para se realizar a seleção em ambas as épocas de semeadura, bem como populações cuja seleção deve ser realizada em épocas específicas.

Em relação ao ambiente de inverno, verifica-se que a população Pioneiro/BRS 207 apresentou a maior contribuição, para a variação total de famílias dentro de populações (Tabela 3), o que possibilita inferir que uma população como essa proporciona êxito com a seleção de linhagens. Isto poderia ser explicado pelo fato de que os dois genitores são, atualmente, recomendados pela pesquisa para o cultivo irrigado (inverno) na Região do Brasil Central. Em condições de verão, essa mesma população apresenta a menor contribuição relativa para a variância; isto evidencia o elevado efeito da alta temperatura sobre suas famílias, o que reduz a expressão de todo o seu potencial genético.

Há populações, como é o caso de BH 1146/BR 24, BR 24/Aliança e Anahuac/BH 1146, que apresentam menor variação e menor contribuição nas duas épocas de semeadura, ou seja, estabilidade na contribuição relativa da variância de um ambiente em relação ao outro. Isto significa que essas populações não respondem ou não expressam grande potencial em condições favoráveis de cultivo (inverno), mas podem ser populações adaptadas (tolerantes) às condições de estresse (verão), por não sofrerem redução ou, até mesmo, aumentarem sua variabilidade no verão, em relação ao inverno (Tabela 3).

Tabela 3. Contribuição relativa de cada população de trigo, para a variância total entre famílias das oito populações segregantes para o caráter produção de grãos, nas semeaduras de inverno e verão.

\begin{tabular}{lcc}
\hline População & \multicolumn{2}{c}{ Contribuição relativa (\%) } \\
\cline { 2 - 3 } & Inverno & Verão \\
\hline BH 1146/BR 24 & 9,00 & 9,00 \\
BR 24/Aliança & 6,53 & 10,60 \\
Aliança/EP 93541 & 6,66 & 16,88 \\
EP 93541/CPAC 9662 & 15,44 & 20,06 \\
CPAC 9662/Pioneiro & 13,46 & 10,48 \\
Pioneiro/BRS 207 & 21,54 & 7,18 \\
BRS 207/Anahuac & 17,64 & 13,79 \\
Anahuac/BH 1146 & 9,72 & 12,00 \\
\hline Total (família/população) & 100 & 100 \\
\hline
\end{tabular}


O ideal é ter populações com ampla variabilidade genética, tanto no cultivo de inverno quanto no de verão. Com base nessa evidência, a população EP 93541/ CPAC 9662 apresenta boa variabilidade no inverno e a maior variância no verão, o que demonstra ser uma população com tolerância à alta temperatura e de grande potencial genético, para a realização de seleção de famílias superiores para as duas épocas de semeadura da cultura do trigo, na Região do Brasil Central.

Os agrupamentos de médias entre as populações segregantes e entre os genitores, para as duas épocas de semeadura, são descritos nas Tabelas 4 e 5. Houve diferenças entre as médias das oito populações segregantes e dos oito genitores, para todos os caracteres avaliados, nas duas épocas de semeadura, o que

Tabela 4. Média de produção de grãos (PG), peso médio dos grãos (PMG), altura de planta (AP) e espigamento (ESP) de oito populações segregantes de trigo, com semeadura no inverno e verão, e os porcentuais de redução na condição de verão, em relação à de inverno ${ }^{(1)}$.

\begin{tabular}{|c|c|c|c|c|}
\hline População & $\begin{array}{c}\mathrm{PG} \\
\left(\mathrm{g} \text { parcela }^{-1}\right)\end{array}$ & $\begin{array}{c}\text { PMG } \\
\left(\mathrm{mg} \mathrm{grão}^{-1}\right)\end{array}$ & $\begin{array}{c}\text { AP } \\
(\mathrm{cm})\end{array}$ & $\begin{array}{c}\text { ESP } \\
\text { (dias) }\end{array}$ \\
\hline & \multicolumn{4}{|c|}{ Semeadura no inverno } \\
\hline BH 1146/BR 24 & $582 d$ & $48 b$ & $124 a$ & $59 b$ \\
\hline BR 24/Aliança & $649 d$ & $45 c$ & $118 b$ & $62 \mathrm{a}$ \\
\hline Aliança/EP 93541 & $855 c$ & $48 b$ & $112 b$ & $60 b$ \\
\hline EP 93541/CPAC 9662 & $875 c$ & $52 \mathrm{a}$ & $106 \mathrm{c}$ & $59 b$ \\
\hline CPAC 9662/Pioneiro & $912 \mathrm{c}$ & $51 \mathrm{a}$ & $107 \mathrm{c}$ & $58 \mathrm{~b}$ \\
\hline Pioneiro/BRS 207 & $1.027 \mathrm{~b}$ & $48 b$ & $97 d$ & $60 b$ \\
\hline BRS 207/Anahuac & $1.154 \mathrm{a}$ & $51 \mathrm{a}$ & $95 d$ & $63 a$ \\
\hline \multirow[t]{2}{*}{ Anahuac/BH 1146} & $660 d$ & $51 \mathrm{a}$ & $115 b$ & $59 b$ \\
\hline & \multicolumn{4}{|c|}{ Semeadura no verão } \\
\hline BH 1146/BR 24 & $473 b$ & $37 b$ & $79 a$ & $49 b$ \\
\hline BR 24/Aliança & $447 \mathrm{c}$ & $35 c$ & $77 \mathrm{a}$ & $51 \mathrm{a}$ \\
\hline Aliança/EP 93541 & $551 \mathrm{a}$ & $37 b$ & $73 b$ & $49 b$ \\
\hline EP 93541/CPAC 9662 & $481 b$ & $40 \mathrm{a}$ & $67 c$ & $46 c$ \\
\hline CPAC 9662/Pioneiro & $426 \mathrm{c}$ & $37 b$ & $62 d$ & $45 d$ \\
\hline Pioneiro/BRS 207 & $370 d$ & $34 c$ & $63 d$ & $44 d$ \\
\hline BRS 207/Anahuac & $426 \mathrm{c}$ & $37 b$ & $69 c$ & $46 c$ \\
\hline \multirow[t]{2}{*}{ Anahuac/BH 1146} & $409 \mathrm{c}$ & $39 a$ & $80 \mathrm{a}$ & $49 b$ \\
\hline & \multicolumn{4}{|c|}{ Porcentuais de redução (\%) } \\
\hline BH 1146/BR 24 & $18,85(1)$ & $22,29(2)$ & $36,48(6)$ & $16,81(1)$ \\
\hline BR 24/Aliança & $31,10(2)$ & $21,38(1)$ & $35,14(5)$ & $18,58(3)$ \\
\hline Aliança/EP 93541 & $35,54(3)$ & $23,17(3)$ & $34,82(4)$ & $19,30(4)$ \\
\hline EP 93541/CPAC 9662 & $45,05(5)$ & $23,61(5)$ & $37,02(7)$ & $22,60(6)$ \\
\hline CPAC 9662/ Pioneiro & $53,25(6)$ & $27,73(7)$ & $42,06(8)$ & $22,40(5)$ \\
\hline Pioneiro/BRS 207 & $64,03(8)$ & $28,99(8)$ & $34,58(3)$ & $26,89(8)$ \\
\hline BRS 207/Anahuac & $63,13(7)$ & $25,74(6)$ & $27,88(1)$ & $26,86(7)$ \\
\hline Anahuac/BH 1146 & $38,06(4)$ & $23,24(4)$ & $30,05(2)$ & $17,51(2)$ \\
\hline
\end{tabular}

evidencia a variabilidade desses genótipos quanto à tolerância ao calor.

Nenhuma população teve o mesmo desempenho em rendimento de grãos, em ambas as épocas de semeadura. Porém, as populações Aliança/EP 93541 e EP 93541/ CPAC 9662 destacaram-se por ter apresentado produções intermediárias no inverno e as maiores produções no verão, tendo mostrado boa tolerância ao calor (Tabela 4).

Para os genitores, foram formados dois grupos de genótipos, nas duas épocas de semeadura (Tabela 5). Neste caso, destacou-se o genitor EP 93541, que esteve no grupo com produtividade superior nas duas épocas, resultante de sua possível maior tolerância à alta temperatura, o que está de acordo com os

Tabela 5. Média de produção de grãos (PG), peso médio dos grãos (PMG), altura de planta (AP) e espigamento (ESP), de oito genitores de trigo, com semeadura no inverno e verão, e os porcentuais de redução, na condição de verão, em relação à de inverno ${ }^{(1)}$.

\begin{tabular}{|c|c|c|c|c|}
\hline Genitor & $\begin{array}{c}\mathrm{PG} \\
\left.(\mathrm{g} \text { parcela })^{-1}\right)\end{array}$ & $\begin{array}{c}\text { PMG } \\
\left(\mathrm{mg} \mathrm{grão}^{-1}\right)\end{array}$ & $\begin{array}{c}\mathrm{AP} \\
(\mathrm{cm})\end{array}$ & $\begin{array}{c}\text { ESP } \\
(\text { dias }) \\
\end{array}$ \\
\hline & \multicolumn{4}{|c|}{ Semeadura no inverno } \\
\hline BH 1146 & $586 b$ & $48 b$ & $133 a$ & $57 \mathrm{c}$ \\
\hline BR 24 & $808 b$ & $45 b$ & $120 b$ & $62 b$ \\
\hline Aliança & $852 b$ & $45 b$ & $115 b$ & $60 b$ \\
\hline EP 93541 & $1.035 \mathrm{a}$ & $45 b$ & $110 \mathrm{c}$ & $59 b$ \\
\hline CPAC 9662 & $1.007 \mathrm{a}$ & $47 \mathrm{a}$ & $93 d$ & $59 b$ \\
\hline Pioneiro & $1.055 \mathrm{a}$ & $52 \mathrm{a}$ & $103 d$ & $57 \mathrm{c}$ \\
\hline BRS 207 & $1.174 \mathrm{a}$ & $47 b$ & $98 \mathrm{~d}$ & $67 \mathrm{a}$ \\
\hline \multirow[t]{2}{*}{ Anahuac } & $745 b$ & $51 \mathrm{a}$ & $100 \mathrm{~d}$ & $65 a$ \\
\hline & \multicolumn{4}{|c|}{ Semeadura no verão } \\
\hline BH 1146 & $459 a$ & $38 \mathrm{a}$ & $75 \mathrm{a}$ & $51 \mathrm{a}$ \\
\hline BR 24 & $458 \mathrm{a}$ & $37 b$ & $80 a$ & $49 a$ \\
\hline Aliança & $424 b$ & $40 \mathrm{a}$ & $75 a$ & $50 \mathrm{a}$ \\
\hline EP 93541 & $518 \mathrm{a}$ & $40 \mathrm{a}$ & $75 \mathrm{a}$ & $50 \mathrm{a}$ \\
\hline CPAC 9662 & $409 b$ & $41 \mathrm{a}$ & $63 b$ & $44 b$ \\
\hline Pioneiro & $347 b$ & $32 c$ & $73 a$ & $42 b$ \\
\hline BRS 207 & $398 b$ & $37 b$ & $70 \mathrm{~b}$ & $49 a$ \\
\hline \multirow[t]{2}{*}{ Anahuac } & $470 \mathrm{a}$ & $36 b$ & $68 \mathrm{~b}$ & $49 a$ \\
\hline & \multicolumn{4}{|c|}{ Porcentuais de redução (\%) } \\
\hline BH 1146 & $21,65(1)$ & $20,64(4)$ & $43,40(8)$ & $11,30(1)$ \\
\hline BR 24 & $43,25(3)$ & $16,28(3)$ & $33,33(6)$ & $20,97(4)$ \\
\hline Aliança & $50,26(5)$ & $12,29(1)$ & $34,78(7)$ & $17,50(3)$ \\
\hline EP 93541 & $49,90(4)$ & $14,45(2)$ & $31,82(3)$ & $15,97(2)$ \\
\hline CPAC 9662 & $59,36(6)$ & $22,03(5)$ & $32,43(4)$ & $26,27(6)$ \\
\hline Pioneiro & $67,15(8)$ & $31,30(8)$ & $29,27(2)$ & $26,32(7)$ \\
\hline BRS 207 & $66,13(7)$ & $27,87(6)$ & $28,21(1)$ & $27,41(8)$ \\
\hline Anahuac & $36,86(2)$ & $29,29(7)$ & $32,50(5)$ & $24,62(5)$ \\
\hline
\end{tabular}

(1)Médias seguidas por letras iguais, na coluna, não diferem estatisticamente entre si, pelo teste de agrupamento de médias de Scott-Knott a $5 \%$ de probabilidade; valores entre parênteses referem-se à classificação crescente dos porcentuais de redução. 
resultados do trabalho de Souza \& Ramalho (2001), que também verificaram a tolerância ao calor desse genótipo.

Os índices de estresse térmico, determinados pela porcentagem de redução da produção de grãos, das populações segregantes e dos genitores no verão, em relação ao inverno, encontram-se nas Tabelas 4 e 5. Constataram-se diferenças expressivas de tolerância ao estresse térmico, entre as populações e entre os genitores, o que demonstra a existência de variabilidade genética e concorda com os resultados de outros trabalhos com a cultura do trigo (Souza \& Ramalho, 2001; Yang et al., 2002).

Os desempenhos das populações segregantes e dos genitores foram muito semelhantes, tanto para o agrupamento de médias dos caracteres avaliados, quanto para os índices de redução, nas duas épocas de semeadura. Isto pode ser evidenciado, por exemplo, pelo fato de a correlação classificatória de Spearman ser alta e positiva $(r=0,88, p \leq 0,01)$, entre os índices de estresse térmico das populações segregantes e dos genitores, para o caráter produção de grãos.

$\mathrm{Na}$ interpretação dos índices de estresse, ficou evidente a sua limitação, visto que em algumas situações, como nas populações BH 1146/BR 24 e BR 24/Aliança (Tabela 4), baixos valores de porcentagem de redução estão associados a baixas produtividades, nas duas épocas de semeadura. Isto mostra que essas populações possuem alta adaptabilidade a ambientes específicos, no caso a semeadura realizada no verão, mas não respondem à melhoria de ambiente, ou seja, semeadura realizada no inverno.

Diante dessa dificuldade, preferiu-se dar ênfase à produtividade obtida no verão. Entre as populações segregantes, podem ser salientados os seguintes cruzamentos: Aliança/EP 93541, EP 93541/ CPAC 9662 e BH 1146/BR 24. Entre os genitores com maior produtividade no verão, podem ser destacados: EP 93541, BH 1146, Anahuac e BR 24, os quais também apresentaram baixo índice de estresse (Tabela 5).

Nas populações destacadas, um ou dois dos genitores possuem boa tolerância ao calor. Isto já era esperado, visto que a correlação classificatória de Spearman apresentou valor elevado e positivo
( $\mathrm{r}=0,88, \mathrm{p} \leq 0,01)$, entre os índices de redução dos genitores e das populações segregantes, para o caráter produção de grãos. Com base nessas evidências, constata-se que o desempenho médio das populações segregantes é semelhante ao dos genitores, ou seja, a escolha dos pais, visando-se gerar variabilidade para tolerância ao calor, para a cultura do trigo, pode ser realizada pela avaliação do desempenho médio dos genitores.

O sucesso de um programa de melhoramento pode estar ligado à avaliação de grande número de indivíduos ou famílias de cada população segregante. Assim, um aspecto a se considerar na escolha das populações segregantes, a serem conduzidas pelo programa, além da variabilidade genética existente nestas populações, é a probabilidade de maior ganho com a seleção. Isto é, uma população será melhor quanto maior for a magnitude do ganho genético (média), para um mesmo diferencial de seleção.

Neste contexto, foram obtidas as médias das dez melhores famílias (33,3\%) de cada população, para o caráter produção de grãos, nas duas épocas de semeadura. Constatou-se que as populações Aliança/ EP 93541 e EP 93541/CPAC 9662 apresentaram as maiores médias no verão e produções intermediárias no inverno (Tabela 6), conforme descrito também na Tabela 4, além de apresentarem elevada variabilidade genética no verão (Tabela 3 ). Isto significa que essas populações possibilitam a seleção de linhagens tolerantes ao calor, com aumento do rendimento de grãos no verão e, igualmente, com elevada produção no inverno.

Tabela 6. Média de produção de grãos (gramas por parcela), das dez melhores famílias de oito populações segregantes, cultivadas no inverno e verão.

\begin{tabular}{lrc}
\hline População & \multicolumn{2}{c}{ Época de semeadura } \\
\cline { 2 - 3 } & Inverno & Verão \\
\hline BH 1146/BR 24 & 721,6 & 546,7 \\
BR 24/Aliança & 780,7 & 538,4 \\
Aliança/EP 93541 & 979,1 & 657,4 \\
EP 93541/CPAC 9662 & $1.067,6$ & 597,7 \\
CPAC 9662/ Pioneiro & $1.071,2$ & 518,1 \\
Pioneiro/BRS 207 & $1.235,0$ & 439,5 \\
BRS 207/Anahuac & $1.374,7$ & 524,9 \\
Anahuac/BH 1146 & 820,3 & 501,9 \\
\hline Média & $1.006,3$ & 540,6 \\
\hline
\end{tabular}




\section{Conclusões}

1. A alta temperatura ocasiona redução em todos os caracteres avaliados no verão, em relação ao inverno, principalmente na produção de grãos.

2. Há diferença de tolerância ao estresse térmico entre as populações e entre os genitores.

3. Os materiais mais tolerantes ao calor são os genitores EP 93541, BH 1146, Anahuac e BR 24, e as populações segregantes: Aliança/EP 93541, EP 93541/ CPAC 9662 e BH 1146/BR 24.

\section{Referências}

BEARZOTI, E. Simulação de seleção recorrente assistida por marcadores moleculares em espécies autógamas. 1997. 230p. Tese (Doutorado) - Escola Superior de Agricultura Luiz de Queiroz, Piracicaba.

CRUZ, C.D. Programa Genes: versão Windows; aplicativo computacional em genética e estatística. Viçosa: UFV, 2001. 648p.

EMBRAPA TRIGO. Trigo do Cerrado alcança novo recorde nacional de produtividade. Viatrigo: Informativo do Centro Nacional de Pesquisa de Trigo, v.1, 2004. Disponível em: <http:// www.cnpt.embrapa.br/informativo/viatrigo/ viatrigo9.htm\#notsemana>. Acesso em: 26 set. 2005.

IBRAHIM, A.M.H.; QUICK, J.S. Heritability of heat tolerance in winter and spring wheat. Crop Science, v.41, p.1401-1405, 2001.

KHANNA-CHOPRA, R.; VISWANATHAN, C. Evaluation of heat stress tolerance in irrigated environment of T. aestivum and related species. I. Stability in yield and yield components. Euphytica, v.106, p.169-180, 1999.

McMASTER, G.S. Phenology, development, and growth of the wheat (Triticum aestivum, L.) shoot apex: a review. Advances in Agronomy, v.59, p.63-118, 1997.

MOTA, F.S. Clima e zoneamento para a triticultura no Brasil. In: OSÓRIO, E.A. (Ed.). Trigo no Brasil. Campinas: Fundação Cargill, 1982. p.27-61.
PIMENTEL-GOMES, F. Coeficiente de variação. In: ESCOLA SUPERIOR DE AGRICULTURA LUIZ DE QUEIROZ. Curso de estatística experimental. Piracicaba, 1990. 7p.

REUNIÃO DA COMISSÃO CENTRO BRASILEIRA DE PESQUISA DE TRIGO, 12., 2002, Uberlândia. Indicações técnicas para a cultura de trigo na região do Brasil Central: safras, 20032004. Passo Fundo: Embrapa Trigo; Brasília: Embrapa Transferência de Tecnologia: Escritório de Negócios do Triângulo Mineiro, 2003. 109 p.

SCOTT, A.J.; KNOTT, M.A. Cluster analysis methods for grouping means in the analysis of variance. Biometrics, v.30, p.507-512, 1974.

SOUZA, M.A. Controle genético e resposta ao estresse de calor de cultivares de trigo. 1999. 152p. Tese (Doutorado) - Universidade Federal de Lavras, Lavras.

SOUZA, M.A. Época de plantio para a cultura do trigo em Minas Gerais. Informe Agropecuário, v.9, p.38-42, 1983.

SOUZA, M.A. Manejo e práticas culturais. Informe Agropecuário, v.5, p.32-35, 1979.

SOUZA, M.A.; RAMALHO, M.A.P. Controle genético e tolerância ao estresse de calor em populações híbridas e em cultivares de trigo. Pesquisa Agropecuária Brasileira, v.36, p.1245-1253, 2001.

STONE, P.J.; NICOLAS, M.E. Comparison of sudden stress with gradual exposure to high temperature during grain filling in two wheat varieties differing in heat tolerance. I. Grain growth. Australian Journal of Plant Physiology, v.22, p.935-944, 1995.

STONE, P.J.; NICOLAS, M.E. The effect of duration of heat stress during grain filling on two wheat varieties differing in heat tolerance: grain growth and fractional protein accumulation. Australian Journal of Plant Physiology, v.25, p.13-20, 1998.

WARDLAW, I.F.; DAWSON, I.A.; MUNIBI, P. The tolerance of wheat to high temperatures during reproductive growth. II. Grain development. Australian Journal of Agricultural Research, v.40, p.15-24, 1989.

YANG, J.; SEARS, R.G.; GILL, B.S.; PAULSEN, G.M. Growth and senescence characteristics associated with tolerance of wheat-alien amphiploids to high temperature under controlled conditions. Euphytica, v.126, p.185-193, 2002.

$\overline{\text { Recebido em } 4 \text { de abril de } 2005 \text { e aprovado em } 26 \text { de maio de } 2006}$ 